\title{
Services and services innovation
}

\author{
Faïz Gallouj · Paul Windrum
}

Published online: 25 September 2008

(C) Springer-Verlag 2008

We have witnessed a dramatic transformation of the USA and western European economies in just twenty years. Built on manufacturing, today these are indubitably services-based economies. The transformation raises a number of important issues for economists, and for evolutionary economists in particular for they have long highlighted the importance of innovation and structural change in their treatment of industrial organisation, employment creation, welfare, economic growth, and international trade. Our understanding of the innovation process, and its economic implications, were built on studies of manufacturing sectors. What needs to be changed? Are some theories and models no longer applicable? Do we need to develop new explanations, theories and models? Is innovation in service sectors fundamentally different to innovation in manufacturing sectors, or is there a set of common features? These are key questions that are now being asked.

We suggest that, by studying services innovation, scholars of innovation have an opportunity to develop an integrated account of innovation that is applicable to both services and manufacturing, and which covers all aspects of the innovative process. This requires a reassessment of established theories and models, and the development and testing of new theories and models. In other words, it requires a thorough review of what (we think) we know about innovation.

\footnotetext{
F. Gallouj $(\varangle)$

University of Science and Technology Lille 1, Lille, France

e-mail: Faiz.Gallouj@univ-lille1.fr

P. Windrum

Manchester Metropolitan University Business School, Manchester, UK

e-mail: p.windrum@mmu.ac.uk
} 
This, at any rate, is our contention, our belief. We do not yet know the answer to the above questions. A tremendous amount of research is needed before a set of clear answers can be proffered. One of the goals of this special issue is to raise the interest of economist not yet working in this area, and to hopefully engage them in it. As the collection of papers contained herein address important, leading edge research topics in services, they will stimulate the interest of economists who are not yet actively researching the area as well as those who are already engaged in services and services innovation research.

This collection of papers is drawn from presentations made at the 2007 EMAEE Conference, which was hosted by the Centre for International Business and Innovation (CIBI) at Manchester Metropolitan University in May 2007. The editors would like to thank the DIME European Network of Excellence, the Netherlands Environmental Assessment Agency, the University of Utrecht, RIBM, and Edward Elgar for their sponsorship of this conference. We would also like to thank the International Schumpeter Society for its continuing sponsoring of the Schumpeter Prize for Best Paper by a $\mathrm{PhD}$ student, and the Consortium on Competitiveness and Cooperation for its sponsorship of the Best Paper by a first/second year PhD student. At the 2007 Conference these were won by Christina Günther and Karl Wennberg respectively.

\section{The papers in this special issue}

The first paper, by Faïz Gallouj and Maria Savona, introduce the key issues and debates that have raged in the services innovation literature over the last 20 years. This provides a clear context for the other papers in the special issue can be placed, and brings them into focus. The Gallouj and Savona paper starts with an overview of a core debate regarding the innovative potential of services, compared to manufacturing, and the implications of this for economic growth and employment. A common concern is that this concern dates back to Adam Smith (1776) and his concern that personal services offered little or no scope for a division of labour and, hence, productivity growth. This concern resurfaced during the 1960s in Baumol's discussion of the 'cost disease'. Baumol (1967) argues that this is due to the lack of innovation (in his words 'technological stagnancy') in services vis-à-vis manufacturing.

Baumol's argument has been questioned in three ways. First, the assumptions have been questioned, theoretically and empirically. Second, a more general issue is raised regarding problems in empirically measuring the outputs of services and in measuring innovation within services-where 'traditional' innovation indicators of patents and $R \& D$ labs expenditures outputs perform poorly. Third, a new exploration of the types of innovation found in services is underway. This debate concerns the issue of whether or not the innovation process in services differs to that in manufacturing, and if, so in what way.

The latter debate has focused around the so-called assimilation/ demarcation/synthesis discussion (Gallouj 1994; Coombs and Miles 2000). The 
'assimilation' viewpoint can be traced back to Pavitt's sectoral taxonomy of innovation (Pavitt 1984). This proposes that service activities are generically the same as manufacturing activities. Theories and empirical indicators, originally developed with manufacturing in mind, are therefore equally applicable to services. Consequently, the study of services can be assimilated within a generic set of theories, originally developed through the study of manufacturing innovation. This is the underpinning methodological basis of the assimilation approach.

Like Baumol, Pavitt argued that services are innovation laggards. Moreover, he argued that, where change occurs, this is typically a consequence of the diffusion of innovations that are developed and first applied in manufacturing sectors. These are acquired through new capital investment or through suppliers (predominantly through pressure exerted by manufacturers up/down the supply chain). Though he later acknowledged computer services, telecoms, and science based services as innovators (Pavitt et al. 1989), he maintained that these were notable because they are exceptions to the rule.

The 'demarcation' viewpoint is the antithesis of the assimilation view. Demarcation writers have forcefully put on the table the proposition that service-specific forms of innovation exist. They have also highlighted the importance of organisational innovation, which appears to go hand-in-hand with product and process innovations in services, and the roles played by knowledge-intensive business service (KIBS) providers and ICTs within the wider innovation process. These areas have become key areas of research.

Demarcation writers argue that completely new, services-specific theories of innovation are required to understand the nature and the dynamics of innovation in services because some forms of innovation are services-specific (see, for example, Gadrey et al. 1995; Sundbo 1998; den Hertog 2000; Preiß1 2000). Two types of innovation have attracted much attention. The first is the co-production thesis. This suggests that a distinguishing feature of services is the high degree of interaction that occurs between the user and the service provider. Particular attention is focused on the business-to-business services provided by knowledge-intensive business service (KIBS) providers. Together with their clients, KIBS detect new needs, define product specifications, and act as an interface between client firms and other actors within innovation networks (e.g. suppliers and business service providers). This highlights the importance of organisational innovation and it relationship to product and process innovation, input and market innovations, innovation networks, and the problems that service firms face in protecting their innovations. A second alleged distinguishing feature is 'ad hoc innovation'. This is a non-reproducible solution to a client-specific problem. The proposition has generated much heated discussion. Drejer (2004), for example, criticises the proposition, observing that it does not conform to the conventional definition of the innovation process where a novelty is introduced that subsequently diffuses across a population. Diffusion requires replication in different settings. This is precluded by the supposed specificity of 'ad hoc innovation'. Drejer argues that what is actually being described here is cumulative learning; a process 
of continuous adaptation to small changes-including coming up with specific solutions to specific problems-and is part of the day-to-day functioning of a business. By contrast, Gallouj and Weinstein (1997) and Gallouj (2002) argue that it is much more than learning. It is innovation characterised by degree of indirect reproducibility.

The 'synthesis' viewpoint, as outlined by Gallouj and Weinstein (1997), Metcalfe (1998), Drejer (2004), and Windrum (2007), seeks to take the recent insights of demarcation writers and to integrate these within insights gained in manufacturing studies within a unifying neo-Schumpeterian framework. This broad framework encompasses the five dimensions of innovation discussed by Schumpeter: organisational, product, market, process and input innovation. According to this view, conventional (manufacturing-based) innovation studies privileged product and process innovation at the expense of organisational, market and input innovation, while services-based innovation studies have (re)invigorated research in these other dimensions. The aim of the neo-Schumpeterian synthesis approach is not merely add one to another, but to develop an integrated account that is applicable to both services and manufacturing, and which covers all aspects of innovative activity. One aspect of this agenda is the re-testing and extension of existing theories and models, originally developed in studies of manufacturing. Another aspect is the development of new theories and models that can accommodate both the services and manufacturing innovations.

The papers in this special issue contribute to this theoretical and empirical debate about the nature of services innovation. The Faïz Gallouj and Maria Savona paper further develops Gallouj's work on extending the Saviotti and Metcalfe (1984) characteristics approach to services innovation. Their aim is to develop a generalisable theory that captures the innovation dynamics of both services and manufacturing sectors, and which is amenable to empirical measurement.

The paper by Nicoletta Corrocher, Lucia Cusmano, and Andrea Morrison examines the types of innovation performed by a sample of KIBS firms in Lombardy. The paper empirically tests a set of propositions that have been put forward in previous literature (discussed above). Using cluster analysis, it tests the importance of different types of innovation amongst KIBS. The authors also test whether a distinction exists between the innovation patterns of two groups of KIBS: professional KIBS (p-kibs), such as business and management services, legal and accounting activities, and market research firms, and technical KIBS (t-kibs) such as IT related services, engineering, and R\&D consulting firms. Two findings are of particular interest. First, not all KIBS innovate. Many rely on their reputation and brand for business. The play that has been made on the importance of KIBS within the services economy may need to be tempered somewhat. Having said this, one should remember that the majority of manufacturing firms do not innovate either. Indeed, one of the most important lessons that innovation studies has taught us is that innovation rates are highly skewed-all the action happens on the tails of the population distribution. A few, highly successful and large firms perform 
the bulk of innovation. ${ }^{1}$ The second finding is that the proposed distinction between p-kibs and t-kibs is not supported by their dataset. With regards to the types of innovation, cluster analysis indicates four key modes of innovation in the sample: product innovation, interactive innovation (i.e. the co-production thesis), technological adoption (Pavitt's argument), and a link between technological and organisational innovation. The findings are intriguing, given the arguments put forward in the assimilation/demarcation/synthesis debate. It is hoped that future empirical studies will seek to replicate the analysis in other regions.

The next two papers examine the long term implications of outsourcing. Outsourcing is, of course, a key issue for services and services innovation. Not only are specialist KIBS the providers of outsourcing services, but the majority of client firms are themselves service firms. The paper by Paul Windrum, Andreas Reinstaller, and Chris Bull reviews the existing empirical literature on short and long terms costs-benefits for the outsourcing firm. These indicate that, while there are short term gains to be had, primarily in terms of reducing the wage bill, firms that heavily engage in outsourcing appears to suffer lower productivity growth than firms that do not engage in outsourcing. Windrum et al. draw a distinction between 'total outsourcing' and 'integrated outsourcing'. The co-production thesis, highlighted by demarcation writers, assumes the client and outsourcing provider have an integrated outsourcing relationship. In fact, this form of open, interactive relationship lies at one end of a spectrum of client-provider relationships. At the opposite end of the spectrum lies the 'total outsourcing' relationship. The vast majority of outsourcing contracts are total outsourcing relationships. In this relationship, the outsourcing firm has little or no control over the outsourced activity for long contractual periods. This severely limits the scope for the outsourcing firm to engage in organisational innovation because these activities cannot be reshaped and recombined with the activities that are held in house. The limits that this places on the scope for organisational innovation has a direct impact on long run productivity growth. The authors test their argument by means of a simulation model. They establish a set of results that correspond to the available empirical data.

The second of the outsourcing paper, by Lars Bengtsson and Mandar Dahbilkar, provides an excellent example of the type of empirical research that is being undertaken. Bengtsson and Dahbilkar examine a survey sample of 267 medium and large size manufacturing firms in Sweden. They distinguish between firms that outsource manufacturing activities, and firms that outsource design as well as manufacturing operations. They compare these two groups of outsourcing firms with firms that do not engage in outsourcing. Taking all outsourcing firms together, cost reduction and increased focus on core activities are cited as key drivers. Despite the emphasis placed on innovation

\footnotetext{
${ }^{1}$ See Coad and Rao (2006) for a recent discussion of the implications of this for statistical analysis of innovation and growth rates.
} 
in the KIBS literature, innovation-related drivers such as reducing time to market, accessing external competences, and learning are not statistically significant. Unfortunately, perceived short term costs are overturned y rising logistics costs and monitoring costs. These are in line with the findings of other surveys. Also in line with other surveys is the finding that outsourcing firms are neither achieving improvements in plant efficiency nor in plant innovation. A particularly intriguing finding of the paper concerns the subsample of firms that outsource design activities as well as manufacturing activities. Some caution needs to be taken here since this sub-sample is small in number $(n=25)$, but there is a suggestion that these firms do experience some positive innovation benefits. This leads Bengtsson and Dahbilkar question to those who have urged firms to keep control of design, $R \& D$, and other core competences in-house. It could be, the authors argue, that the outsourcing of related activities enables improvements to be made (the identification of the externalities discussed by Windrum et al.) that would be unavailable if piecemeal outsourcing is undertaken. Alternative, it could be that these are poorly performing firms, and so outsourcing activities to another firm improves their competitive performance. Testing this requires discriminatory analysis and a larger sample. Regardless, it opens up an interesting and important issue that demands further empirical research.

The paper by Karl Wennberg is an example of research originally developed with respect to manufacturing firms, being applied to services firms. In this particular instance, Wennberg extends and develops the work of Klepper on firm spin-outs. Klepper's thesis of entrepreneurial success-that founders that leave successful, innovative firms to start up their own businesses in the same industry have a higher probability of success than entrepreneurs without this background-is here combined with theories of human capital, and applies to a discussion of the role played by knowledge in new financial services ventures. Wennberg's dataset comprises matched employee-employer information on 1,077 financial services ventures in Sweden for the period 1990 to 2002. The findings suggest that larger founding teams, with more extensive knowledge gained from past employment in the financial services is a factor affecting success. But so is knowledge gained from past employment in hightech industries. Indeed, it is this combination of knowledge which appears to be very powerful, markedly increasing the probability of survival. This idea that particular combinations of knowledge and past industry experience are important certainly extends the current discussion on spin-out entrepreneurship, and of entrepreneurship in services.

The final two papers extend the focus outwards: to services innovations in networks. Each, in its own way, takes the discussion beyond KIBS. The paper by Rebeca Mendez-Duron and Clara García addresses the importance of social capital within the open source community, and its impact on the success of open source software projects. The authors argue social capital establishes a set of ties among programmers who make up an innovation network. There are central actors, and more peripheral actors, strong ties and weak ties. Together these establish a directionality of knowledge flows, inwards and outwards, 
within open source projects. Data on games' software development is collected from SourceForge.net over a twelve month period. This provides dataset of 2,962 observations. By treating an individual project as one event, in a flow of such events across a network, the authors project a two-mode network into a one-mode event-by-event network. The findings indicate asymmetric knowledge flows across projects, reflecting the different roles played by core project members and by contributors. Contributors who add programming expertise (a key source of new knowledge) raise the likelihood of project success. By contrast, if core members simultaneously sign up to other projects, this tends to hinder project success. The exception is where programming activities in other projects develops new knowledge that can be transferred back.

The final paper, by Davide Consoli and Andrea Mina, provides a very exciting and promising area of services research: health. It is novel in two senses. First, it explicitly considers interactions between public and private sector organizations. With the exception of university science, innovation in the public sector is woefully under-researched, while a consideration of interactions between public and private sectors innovation networks is nonexistent (Windrum 2008). This paper addresses precisely this topic. Health sector innovation comprises complex bundles of new medical technologies and clinical services that are created by a highly distributed public-private competence base. Second, the paper is novel in the algorithms that are used to analyse networks. Going beyond traditional centrality measures, the methods enable one to identify chains of citations through time, presenting us with a picture of the history-dependent trajectories that develop in a medical field. The paper therefore offers up a new topic for study within services, and new, promising techniques with which to study the topic.

Acknowledgements The Guest Editors would like to thank Uwe Cantner and Andreas Pyka for their support throughout the process. Also, many thanks to all of the referees for their cooperation and contributions. Without their support it would not have been possible to produce this Special Issue so efficiently.

\section{References}

Baumol WJ (1967) Macroeconomics of unbalanced growth: the anatomy of an urban crisis. Am Econ Rev 57:415-426

Coad A, Rao R (2006) Innovation and market value: a quantile regression analysis. Econ Bull 15(13):1-10

Coombs R, Miles I (2000) Innovation, measurement and services: the new problematique. In: Metcalfe JS, Miles I (eds) Innovation systems in the service economy. Kluwer, Boston, pp 85-103

den Hertog P (2000) Knowledge intensive business services as co-producers of innovation. Int J Innov Manag 4:491-528

Drejer I (2004) Identifying innovation in surveys of services: a Schumpeterian perspective. Res Policy 33(3):551-562

Gadrey J, Gallouj F, Weinstein O (1995) New models of innovation—how services benefit industry. Int J Serv Ind Manag 6(3):4-16 
Gallouj F (1994) Economie de l'innovation dans les services, Editions L'Harmattan, Logiques Économiques, Paris. (English language version: Gallouj F (2002) Innovation in the service economy: the new wealth of nations. Edward Elgar, Cheltenham)

Gallouj F (2002) Innovation in the service economy: the new wealth of nations. Edward Elgar, Cheltenham

Gallouj F, Weinstein O (1997) Innovation in services. Res Policy 26:537-556

Metcalfe JS (1998) Evolutionary economics and creative destruction. Routledge, London

Pavitt K (1984) Sectoral patterns of technical change: towards a taxonomy and a theory. Res Policy $13: 343-374$

Pavitt K, Robson M, Townsend J (1989) Technological accumulation, diversification and organisation in UK companies. Manag Sci 35:81-99

Preiß1 B (2000) Service innovation: what makes it different? Empirical evidence from Germany. In: Metcalfe JS, Miles I (eds) Innovation systems in the service economy: measurement and case study analysis. Kluwer, Boston

Saviotti PP, Metcalfe JS (1984) A theoretical approach to the construction of technological output indicators. Res Policy 13:141-151

Smith A (1776) An enquiry into the nature and causes of the wealth of nations. Clarendon, Oxford

Sundbo J (1998) The organisation of innovation in services. Edward Elgar, Cheltenham

Windrum P (2007) Innovation in services. In: Hanusch H, Pyka A (eds) The Edward Elgar companion to neo-Schumpeterian economics. Edward Elgar, Cheltenham

Windrum P (2008) Innovation in public services. In: Windrum P, Koch $\mathrm{P}$ (eds) Innovation in public services: management, creativity, and entrepreneurship. Edward Elgar, Cheltenham 